\title{
SOIL SPECTRAL IMAGING: MOVING FROM PROXIMAL SENSING TO SPATIAL QUANTITATIVE DOMAIN
}

\author{
E. Ben Dor ${ }^{\mathrm{a}, *}$ \\ ${ }^{a}$ Department of Geography and Human Environment, Tel Aviv University, Ramat Aviv Tel Aviv \\ bendor@post.tau.ac.il
}

Commission VII, WG VII/3

KEY WORDS: Soil Spectroscopy, Imaging Spectroscopy (IS), Near Infrared Spectroscopy (NIRS), Soil Properties

\begin{abstract}
:
Imaging spectroscopy (IS) is a relatively new technique that has attracted the attention of workers in many fields. In the soil sciences, this technology is not well developed and additional research is required - despite the fact that a large number of soil properties in the soil environment have already been studied from a reflectance perspective with much success (e.g. organic matter, cation exchange capacity, carbonate content and specific surface area). Going from proximal sensing to image spectrometry is not only a journey from the micro to macro scales; it is a lengthy one that is fraught with problems, such as dealing with data having a low signal-to-noise level, contamination of the atmosphere, large data sets, the Bidirectional Reflectance Distribution Function (BRDF) effect and more. In this paper, provide a brief history of both near infrared spectroscopy (NIRS) and IS approaches and attempt to understand why, despite its promise, IS has not yet been well developed for the soil sciences. We assume that research, education, exposure of the technology to end-users and governmental involvement are the major factors that require attention in this venue. Also provide some personal thoughts on the future of IS in soil and conclude that in 5 to 10 years, this application will have matured into one that is ready to use and well-known among soil scientists, end-users and decision-makers.
\end{abstract}

\section{INTRODUCTION}

\subsection{Imaging Spectroscopy}

Imaging spectroscopy (IS), or hyperspectral remote sensing (HRS), is an advanced tool that provides high spectral resolution data in an image, with the aim of providing nearlaboratory-quality reflectance or emittance for each individual picture element (pixel) from a far or close distances (Vane et al., 1984). This information enables the identification of objects based on the spectral absorption features of chromophores and has found many uses in terrestrial and marine applications (Clark and Roush, 1984, Vane et al., 1984, Dekker et al., 2001). Figure 1 illustrates the concept, in which the spectral information of a given pixel shows a new dimension that cannot be obtained by traditional point spectroscopy, air photography or other multi-band images. IS can thus be described as an "expert" Geographic Information System (GIS) in which layers are built on a pixel-by-pixel basis, rather than on a selected group of points (McBratney et al., 2003). This enables spatial recognition of the phenomenon in question with a precise spatial view and use of the traditional GIS interpolation technique in precise thematic images. Since the spatial-spectral-based view may provide better information than viewing either the spatial or spectral view separately, IS serves as a powerful and promising tool in the modern remote-sensing arena. Since 1983, when the first airborne IS sensor (AIS, Vane and Goetz 1984) ushered in the IS era (Vane et al., 1984), this technique has been used mostly for geology, water, and vegetation applications. It appears that its application did not extend to soils because these present a complex matrix: it is only recently, with the advent of better signal-to-noise sensors, the manufacture of less expensive IS sensors and the development many soil (point) spectroscopy applications, that soil-IS activity has progressed somewhat.

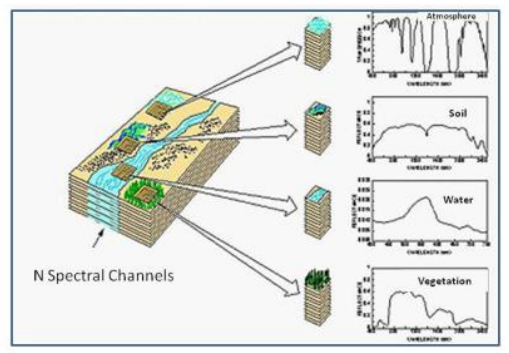

Figure 1. The IS concept: an IS image is composed of $\mathrm{N}$ spectral bands that generate a spectral cube. For each pixel, a spectrum can be extracted representing a spectral footprint of the object (taken from JPL: AVIRIS concept)

\section{QUANTITATIVE ASPECTS OF PROXIMAL SOIL SPECTROSCOPY-}

\subsection{Historical Notes}

Today, soil spectroscopy is a mature discipline which has come quite a long way since the mid-1960s, when Bowers and Hanks (1965) published their paper on the correlation between soil reflectance and soil moisture content. That

\footnotetext{
* Corresponding author. This is useful to know for communication with the appropriate person in cases with more than one author.
} 
innovative study, followed by a series of papers by Hund and Salisbury (1970-1980) (Hunt 1980), proved that water and minerals in soil environment have unique spectral fingerprints that can be further used for specific recognition. In parallel to this development, Ben-Gera and Norris (1968) published a paper showing a correlation between the reflectance reading and moisture content in soybeans. Based on this finding, a new discipline-near-infrared spectroscopy (NIRS)emerged, focusing on extracting quantitative information from reflectance data, first in the food sciences and then in other disciplines. The first conference to gather together scientists in this field was held 1987 in Norwich, UK: The First International Near-Infrared Spectroscopy Conference. Today, many conferences, workshops and scientific meetings are dedicated to the NIRS concept, along with a specialized scientific journal dedicated to the NIRS method which was established in 1993 (The Journal of Near Infrared Spectroscopy). In 1987, Davies published an article in European Spectroscopy News entitled "Near Infrared Spectroscopy Analysis: Time for the Giant to Wake Up." He appealed to potential users at that time to use reflectance spectroscopy across the Near Infrared wavelength region for chemical analysis of powders. A decade later, Davies (1998) published another article entitled "The History of Near Infrared Spectroscopic Analysis: Past, Present and Future 'From Sleeping Technique to the Morning Star of Spectroscopy'" that proved that the NIRS technique had come a long way and that the quantitative optical approach (mostly for food products) was mature, successful and applicable. The disciplines that made use of NIRS were: food sciences, pharmacology, textiles, tobacco, the oil industry, agriculture, art, the paper industry and more. Learning from these sectors' successes, Dalal and Henry applied the NIRS approach to soils in 1986 (Dalal and Henry, 1986). This pioneering study captured the attention of many researchers who realized the potential of soil reflectance spectroscopy. The first scientists to systematically gather soil spectral information and publish it in the form of a soil spectral atlas were Stoner et al. (1980). Their soil spectral library very soon became a classic tool that soil scientists came to rely on. Later, when laboratory and portable field spectrometers were introduced into the market (around 1993), more scientists realized the potential of soil spectroscopy, and consequently more spectral libraries were assembled. In April 2008, a world soil spectroscopy group was established by Viscarra Rossel (http://groups.google.com/group/soil-spectroscopy) who gathered soil spectra and corresponding attributes from more than 80 countries worldwide in order to generate a global soil spectral/attribute database providing soil-NIRS capability to all. This initiative was based on the idea that the NIRS approach in soil sciences was well established and applicable and that it should be more collaborative. Comprehensive reviews on NIRS soil applications can be found in Malley et al. (2004) and Viscarra Rossel et al., (2006), and other important reviews focusing on soil reflectance theory and applications can be found in Irons et al. (1989), Ben-Dor et al. (1999), and Ben-Dor (2002).

\subsection{Limitations of IS}

It appears that the limited number of studies in soil-IS applications (relative to other disciplines such as geology, vegetation and water) is due to the difficulties encountered on the journey from point spectroscopy to a cognitive (imaging) spectral view of soils. The IS approach is still a costly method, it is difficult to process, is operated by only a few sensors worldwide, and has not yet been recognized by many end-users. The relatively low signal-to-noise ratio, atmospheric attenuation, a varying field of view for every pixel, spectral instability, low integration time for a given pixel, spectral mixing problems, optical shifts from one pixel to another, and BRDF effects are only a few of the problems. The relatively low spatial resolution from air and space domains with low geo-location accuracy also hinders accurate mapping with the IS approach. IS data require fine pre-processing of the raw data prior to any advanced correction. Highly skilled personnel are needed to meet all of these requirements, with experience, knowledge, and a well-equipped infrastructure (software and field measurements). In addition, it should be remembered that the soil surface is not always flat, smooth, or homogeneous and therefore sample preparation (as performed in the laboratory) is almost impossible. This leads to problems such as variations in particle size, adjacency, BRDF effects, and the need to develop methodologies that will represent a pixel on the ground and in the IS sensor from both the chemical and spectral perspectives. In the face of all of these obstacles, one should remember that although optical remote sensing does not go beneath the surface, it can eventually render precise soil (profile) mapping. This can be done if more electromagnetic methods are combined to the IS as well as if smart approaches, such as the spectral penetrating probe assembly presented by Ben-Dor et al., 2008 et al is used. Another important problem is the validation-stage assessment. Since the pixel size cannot really represent point measurements, at least $3 \times 3$ pixels have to be averaged for both true spectral ground measurements and chemical analysis. Since a field may generate a non-homogeneous presentation, this can cause problems that, if not estimated properly, will bias the final "spectral-based" map.

\section{THE FUTURE OF SOIL-IS: SOME NOTES}

Despite the abovementioned obstacles, we feel that IS technology for soil applications is highly promising. This is based on the idea that the spectral properties of soils, the innovative progress in quantitative analysis of soils from a spectral perspective, and the recent advances in IS sensors will create a valuable environment for innovative studies and practical applications in the soil sciences. This stage is achievable if the abovementioned problems can be solved. The remarkable achievements in IS sensor manufacturing are evidenced by the many relatively lowcost IS sensors which are now commercially available (for example SPECIM, a well-known IS producer, has sold more than 70 sensors over the past 5 years). The introduction of unmanned airborne vehicles with simple operation capabilities and ground-sensor availability has become the driving force in IS technology. Separation between pre-processing of IS data (including atmospheric rectification) and quantitative analysis is recommended. This can be achieved by collaborating or purchasing such a service in advance (for example DLR offers this service for airborne IS remote sensing data) . Likewise, developing full-chain capability from raw to 
reflectance data is strongly recommended if IS becomes a major vehicle for the potential user. The current drawback of high operational costs is diminishing as the technology develops. Software to analyze IS data is available today for simple or complex applications and for spectral and spatial analyses, atmospheric correction, BRDF and geometrical rectification. It is true that professional manpower is still required to collect and analyze the IS data, but where this was a limitation a few years ago, today, IS is part of the teaching program in most universities worldwide, with many dissertations being written on the topic. The most critical limitation today is the commercial aspect: this refers to the practical implementation of IS technology for other than scientific research. This can be solved by educating the market and exposing end-users to this technology's potential in order to prove that it can provide better economic benefits than traditional methods. The problem of sensing the soil profile can be solved by merging IS technology with other remote-sensing techniques as was done by Ben-Dor et al. (2008) for soil salinity (using Ground Penetrating Radar (GPR) and Frequent Domain Electro Magnetic (FDEM) antenna, as well as by developing new approaches, such as combining the IS information with point spectroscopy in the field. Another point of note is that the spectral range available today (VIS-NIR-SWIR) can be enlarged to both UV $(<300$ $\mathrm{nm}$ ) and thermal (TIR 2500-14000 nm) spectral regions providing more quantitative information about the soils. Moving from airborne to ground IS sensors may also create new applications for soil mapping. A new initiative to put an IS sensor into orbit (e.g. EnMAP, Stuffler et al., 2009) is more good news that will generate high signal-to-noise spectral information on soils with high temporal resolution and wide spatial coverage. In summary, it can be said that although IS for soil applications is still in its juvenile stage, it holds great potential as an innovative vehicle to study soils from afar in a quantitative domain.

\section{SUMMARY AND CONCLUDING REMARKS}

Based on the accumulated knowledge presented in this paper, we feel strongly that soil-IS applications are unlimited. Towards this goal, the following partial milestones remain to be achieved: breakthroughs in technology (to achieve nearlaboratory-quality data from the air and orbit at a reasonable cost), training the younger generation (to give to those who will soon be decision-makers a proper background), educating the market (to make more end-users aware of this promising technique), developing new applications (to extend the IS technology to more end-users and sectors), and generating a strong lobby among those who control governmental funds (to allocate more resources to the IS domain under a national umbrella). Although this list is valid for any IS application (geological, urban, vegetation, snow, water, etc.), for soil applications, one additional important task must be performed: opening the minds of soil scientists to the possibilities afforded by these innovative tools (to strengthen IS technology in the community of soil scientists) and interacting with potential end-users (to judge whether science has reached real-world applications). We strongly believe that these milestones can be achieved in a period of 5 to 10 years. By means of this paper, we have the privilege of making the entire soil science community aware of this important field by adopting Davies 1987 wording saying: "Soil Spectral Imaging Analysis: Time for a Giant Wake-up Call!"

\section{Reference}

\section{References from Journals:}

Ben-Dor,E.(2002) Quantitative remote sensing of soil properties. Advances in Agronomy 75:173-243

Ben-Dor, E., Chabrillat, S., Demattê, J.A.M., Taylor, G.R., Hill, J., Whiting, M.L., and Sommer, S. (2009) Using imaging spectroscopy to study soil properties. Remote Sensing of Environment 113:38-55.

Ben-Dor, E., Patkin, K., Banin, A., and Karnieli, A. (2002) Mapping of several soil properties using DAIS7915 hyperspectral scanner data. A case study over clayey soils in Israel. International Journal of Remote Sensing 23:1043-1062

Ben-Dor E., D. Heller and A. Chudnovsky, (2008), A novel method of classifying soil profiles in the field using optical means. Soil Science Society of American Journal 72:1-13

Ben-Dor, E., Chabrillat, S., Demattê J.A.M. Taylor, G.R., Hill J., Whiting, M.L., and Sommer, S. (2009), Using Imaging Spectroscopy to Study Soil Properties. Remote Sensing of Environment 113:38-55.

Ben-Gera, I. and Norris, K.H. (1968) Determination of moisture content in soybeans by direct spectrophotometry. Israeli Journal of Agriculture Research 18:124-132

Bowers, S., and Hanks, R.J. (1965) Reflectance of radiant energy from soils. Soil Science 100:130-138

Clark, R.N., and Roush, T.L. (1984) Reflectance spectroscopy: quantitative analysis techniques for remote sensing applications. Journal of Geophysical Research 89:6329-6340

Dalal, R.C., and Henry, R.J. (1986) Simultaneous determination of moisture, organic carbon and total nitrogen by near infrared reflectance spectroscopy. Soil Science Society of America Journal 50:120-123

Davies, A.M.C (1987) Near infrared spectroscopy analysis: time for the giant to wake up. European Spectroscopy News 73:10-16

Davies, T. (1998) The history of near infrared spectroscopic analysis: Past, present and future "From sleeping technique to the morning star of spectroscopy." Analysis Magazine 26(4)17-19

Kemper, T., and Sommer, S. (2002) Estimate of heavy metal contamination in soils after a mining accident using reflectance spectroscopy. Environmental Science \& Technology 36:2742-2747

McBratney A.B., Mendonca Santos M.L. and B. Minasny, 2003, On digital soil mapping. Geoderma $117: 2-52$ 
Palacios-Orueta, A., Pinzon, J.E., Ustin, S.L., and Roberts, D.A. (1999) Remote sensing of soil properties in the Santa Monica mountains: II. Hierarchical foreground and background analysis. Remote Sensing of Environment 68:138151

Stoner, E.R., Baumgardner, M.F., Biehl, L.L., and Robinson, B.F. (1980) Atlas of soil reflectance properties. Research Bulletin 962, Agricultural Experiment Station, Indiana Research, Purdue University, West Lafayette.

Stuffler, T., Förster, K., Hofer, S., Leipold, M., Sang, B., Kaufmann, H., Penné, B., Mueller, A., and Chlebek, C. (2009) Hyperspectral imaging - an advanced instrument concept for the EnMAP mission (Environmental Mapping and Analysis Programme). Acta Astronautica 65:7-8, 11071112

Ustin, S.L., and Schaepman, M.E. (2009) Imaging spectroscopy: special issue. Remote Sensing of Environment $113: 1-3$

Vane, G., Goetz, A.F.H., and Wellman, J.B. (1984) Airborne imaging spectrometer: a new tool for remote sensing. IEEE Transactions on Geoscience and Remote Sensing 22(6):546549

Viscarra Rossel, R.A, Walvoort, D.J.J., Mcbratney, A.B., Janik, L.J., and Skjemstad, J.O. (2006) Visible, near infrared, mid infrared or combined diffuse reflectance spectroscopy for simultaneous assessment of various soil properties. Geoderma 131:59-75

\section{References from Books}

Ben-Dor E.,J.A. Irons and A. Epema, (1999), Soil Spectroscopy. In: Manual of Remote Sensing, Third Edition, A. Rencz (ed.) J. Wiley \& Sons Inc. New-York, Chichester, Weinheim, Brisbane, Singapore, Toronto. pp.111-188

Ben-Dor, E., Goldshleger, N., Eshel, M., Mirablis, V., and Bason, U. (2008) Combined active and passive remote sensing methods for assessing soil salinity. In : Metternicht, G., and Zinck, A. (Eds), Remote Sensing of Soil Salinization: Impact and Land Management. CRC Press, USA pp.235256.

Dekker, A.G., Brando, V.E., Anstee, J.M., Pinnel, N., Kutser, T., Hoogenboom, H.J., Pasterkamp, R., Peters, S.W.M., Vos, R.J., Olbert, C., and Malthus, T.J. (2001) Imaging spectrometry of water. In: Imaging Spectrometry: Basic Principles and Prospective Applications: Remote Sensing and Digital Image Processing, Vol. IV, Ch. 11. Kluwer Academic Publishers, Dordrecht, pp. 307-358.

Hunt R.G. 1982, Spectroscopic properties of rocks and minerals. In "Hand Book of Physical Properties of Rocks Minerals CRC Press Boca Raton pp 295-385.

Irons, J.R., Weismiller, R.A., and Petersen, G.W. (1989) Soil reflectance In: Asrar, G. (Ed), Theory and Application of Optical Remote Sensing. Wiley Series in Remote Sensing, John Wiley \& Sons, New York, pp. 66-106

Malley, D., Martin, P.D., and Ben-Dor, E. (2004) Application in analysis of soils. In: Craig, R., Windham, R., and
Workman, J. (Eds), Near Infrared Spectroscopy in Agriculture, Ch. 26. Agronomy Monograph 44, pp. 729784. 